\title{
Somogy megye kószalegyeinek katalógusa (Diptera: Rhagionidae)
}

\author{
MAJER JÓZSEF
}

\begin{abstract}
MAJER J.: Checklist of snipe-flies of Somogy county (Diptera: Rhagionidae)
Abstract: From the 12 snipe-fly species known in Hungary, 9 were recorded in Somogy county. They are mostly small or medium-sized, slender, fragile, more or less long-shaped $(2-20 \mathrm{~mm})$. Some species have not been published yet. These can be found in the collection of the Natural History Museum of Hungary, determined by Majer J.. Rhagionidae is a family of flies that occurs seldom, for a very short period and most of them are solitary. These flies are usually seen resting, facing downwards on a post or tree trunk waiting to spot a suitable item of prey. The larvae, generally living in mud and leaf mould on the woodland floor, prefer carnivorous diet.
\end{abstract}

\section{Bevezetés}

A Rhagionidae család revízióját követően az ide tartozó nemek száma jelentôsen lecsökkent. Korábban LiNDNER (1925), MAJER (1977), ROZKOŠNÝ, \& SPITZER, (1965), SZILÁDY (1934) által az e családba sorolt Coenomyia, Xylophagus, Atherix és Athrichops nemek származásukat tekintve joggal kerültek 3, másik önálló családba (MAJER 1988, 1997). A családot hazánkban 12 faj képviseli, ezek közül eddig 9-et sikerült Somogy megyéból is kimutatni, de a többi faj elôkerülése sem zárható ki. A család képviselói nedves, párás helyeken, többnyire magánosan élnek, gyakran ülnek fejjel lefelé a fák törzsén. Lárváik talajban fejlódnek, ragadozók, vagy szerves anyagokat fogyasztanak. Somogy megye vizes élőhelyei, égerláp foltjai különösen kedvezó élőhelyei ezeknek a legyeknek. Az itt felsorolt fajok többsége a Magyar Természettudományi Múzeum Állattára gyúiteményében találhatók, az anyagot MAJER határozta meg. A megyéból publikált adat a Barcsi borókásból (MAJER, 1985), továbbá a Balaton mellékérốl (MAJER, 1977) van. Felvettük a listára azokat a fajokat amelyeket eddig még nem publikáltak, de valamely hazai gyújteményben fellelhetô és a szerzó határozta meg. Ezek neve alá évszám nélkül írtuk a MAJER nevet.

\section{Somogyból ismert fajok jegyzéke}

\author{
Rhagionidae \\ Rhagio annulatus (De Geer, 1776) - Majer, 1985 \\ Rhagio lineola Fabricius, 1794 - Majer, 1985 \\ Rhagio inmaoulatus Meigen, 1804-Majer 1985 \\ Rhagio scolopaceus (Linné, 1758) - Majer, 1985
}

\author{
Rhagio strigosus Meigen, 1804 - Majer, 1985 \\ Rhagio tringarius (Linné, 1758) - Majer, 1977 \\ Rhagio vitripennis (Meigen, 1820) - Majer, 1985 \\ Crysopitus caunatis (Fabricius, 1805) - Majer, 1985 \\ Chrysopilus luteolus (Fallén, 1814) - MAJER, 1977
}




\section{1. táblázat: Somogyból ismert fajok száma}

\begin{tabular}{|l|c|}
\hline Rend, Család & Fajszám \\
\hline Diptera & \\
\hline Rhagionidae & 9 \\
\hline
\end{tabular}

\section{Irodalom}

LINDNER, E. 1925: 20. Rhagionidae. In Lindner, E. (ed.): Die Fliegen der palaearktischen Region, 4(1): 1-49. MAJER, J. 1977: Katonalegyek - Gömblegyek. Fauna Hungariae Akadémiai Kiadó, XIV/10. pp. 75. MAjER, J. 1985: A Barcsi Borókás katonalégy (Stratiomyidae), kószalégy (Rhagionidae) és rablólégy (Asilidae) faunája (Diptera). - Dunántúli Dogozatok Természettudományi Sorozat, 5: 139-144. Majer, J. 1988: Family Rhagionidae. In Soós Á. and Papp L., Catalogue of Palaearctic Diptera.. Akad. Kiadó Budapest, Vol. 5. p. 14-29.

Majer, J. 1997: Rhagionidae. in: Papp-Darvas: Contribution to a Manual of Palaearctic Diptera, Vol.2.: 433-439. Science Herald Publisher, Bp.

RozKošnÝ, R. and SpITzer, K. 1965: Schnepfenfliegen (Diptera, Rhagionidae) in der Tschechoslowakei. Acta ent. bohemoslov., 62: 340-368.

SzILÁDY, Z. I934: Die palaearktischen Rhagioniden. Annls. hist.-nat. Mus. natn. hung., 28: 229-270.

\section{Checklist of snipe-flies of Somogy county (Diptera: Rhagionidae)}

JÓZSEF MAJER

The family occurs in wet areas. Hitherto 12 species are known from Hungary of which 9 were recorded in Somogy county. They are reported from few places in the county due to the sporadic collecting.

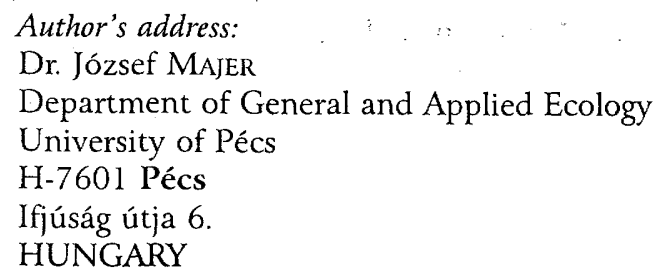

